\title{
PENGARUH PEMBIAYAAN BAGI HASIL DAN TINGKAT KESEHATAN BANK TERHADAP KINERJA KEUANGAN DENGAN PEMBIAYAAN BERMASALAH SEBAGAI VARIABEL PEMODERASI
}

\author{
Dian Ratri Utami \\ Program Studi S1 Akuntansi Fakultas Ekonomi Universitas Pamulang \\ dianratri25@gmail.com \\ Tri Utami \\ Program Studi S1 Akuntansi Fakultas Ekonomi Universitas Pamulang \\ dosen00882@unpam.ac.id
}

\begin{abstract}
Abstrak: Pengaruh Pembiayaan Bagi Hasil Dan Tingkat Kesehatan Bank Terhadap Kinerja Keuangan Dengan Pembiayaan Bermasalah Sebagai Variabel Pemoderasi Penelitian ini bertujuan untuk mengetahui pengaruh dari variabel independent yaitu pembiayaan bagi hasil dan tingkat kesehatan bank terhadap kinerja keuangan dengan pembiayaan bermasalah sebagai variabel pemoderasi. Populasi yang menjadi obyek dalam penelitian ini adalah Bank Umum Syariah di Indonesia sebanyak 14 Bank yang terdaftar dalam Bank Indonesia. Pengumpulan data dengan metode purposive sampling. Sampel yang digunakan adalah 11 Bank Umum Syariah yang memiliki data sesuai dengan variabel yang dibutuhkan. Metode analisis data yang digunakan yaitu Moderated Regression Analysis (MRA). Penelitian ini menunjukan 1) Pembiayaan bagi hasil tidak memiliki pengaruh tehadap kinerja keuangan (ROA). 2) Tingkat kesehatan bank memiliki pengaruh positif signifikan pada profitabilitas kinerja keuangan perusahaan. 3) Pembiayaan bermasalah (NPF) secara simultan tidak berhasil memperkuat pengaruh pembiayaan bagi hasil terhadap kinerja keuangan. 4) Pembiayaan bermasalah (NPF) secara simultan juga tidak dapat memperkuat pengaruh tingkat kesehatan bank terhadap kinerja keuangan.
\end{abstract}

Kata kunci: Pembiayaan Bagi Hasil, Capital Adequacy Ratio (CAR), Non Performing Financing (NPF), Retun On Asset (ROA)

Abstract: Effect of Profit Sharing Financing and Bank Health Level on Financial Performance with Problem Financing as Moderating Variables. This study aims to determine the effect of the independent variable, profit sharing financing and bank soundness on financial performance with problem financing as a moderating variable. The population that is the object of this study is 14 Sharia Commercial Banks in Indonesia, which are registered with Bank Indonesia. Data collection using purposive sampling method. The sample used was 11 Islamic Commercial Banks that have data in accordance with the required variables. The data analysis method used is Moderated Regression Analysis (MRA). This study shows 1) Profit sharing financing has no influence on financial performance (ROA). 2) The level of soundness of a bank has a significant positive effect on the profitability of a company's financial performance. 3) Simultaneous financing (NPF) does not succeed in strengthening the effect of profit sharing financing on financial performance. 4) Simultaneous financing (NPF) also cannot strengthen the effect of bank soundness on financial performance.

Keywords: Profit Sharing Financing, Capital Adequacy Ratio (CAR), Non Performing Financing $(N P F)$, Retun On Asset (ROA)

\section{PENDAHULUAN}

Fenomena yang muncul saat ini adalah perkembangan perbankan syariah di Indonesia dan hampir menjadi gaya hidup di masyarakat modern. Muncul keinginan masyarakat untuk menanamkan modal dan investasinya yang terbebas dari unsur riba yang selama ini dikembangkan oleh bank 


\section{Nominal: Barometer Riset Akuntansi dan Manajemen \\ P-ISSN: 2303-2065 E-ISSN: 2502-5430 \\ Volume 10 No 2 (2021)}

konvensional yaitu berupa bunga bank. Karena MUI sudah mengeluarkan fatwa bahwa bunga bank termasuk dalam riba dan hukumnya haram, masyarakat yang taat lebih memilih berpindah menuju bank syariah sebagai lembaga pembiayaan yang bebas dari unsur riba. Persaingan yang semakin kuat antara bank syaiah berpengaruh sacara langsung ataupun tidak terhadap tercapainya profitabilitas bank Syariah (Rochmanika \& Rahman, 2012).

Disahkannya undang-udang nomor 21 tahun 2008 tentang perbankan syariah merupakan salah satu faktor yang menyebabkan perkembangan perbankan sayariah di Indonesia semakin pesat (Nizar \& Anwar, 2015). Menurut Utami (2014), perkembangan pasar keuangan juga telah menggerus eksistensi keberadaan bank konvensional karena perubahan yang cepat di pasar keuangan dalam hal volume, nilai transaksi dan jenis aset yang diperdagangkan. Meningkatnya jumlah mata uang dan pasar modal memungkinkan bank konvensional untuk mengurangi pinjaman tradisional, itulah sebabnya konsumen beralih ke lembaga keuangan lain, terutama bank syariah. Pembiayaan memiliki kontribusi besar terhadap profitabilitas suatu bank. Hampir semua dana dari masyarakat yang ada pada bank di salurkan kembali melalui pembiayaan. Hal ini yang menjadikan sebagian besar bank syariah masih mengandalkan sumber pendapatan utamanya dari operasi pembiayaan.

Terlihat (gambar 1) bahwa pembiayaan musyarakah mengalami kenaikan setiap tahun yang berarti nasabah dan perbankan lebih memilih kerja sama dimana keduanya saling berkonstribusi dan juga karena pembiayaan musyarakah memiliki risiko yang lebih kecil dibandingkan pembiayaan mudharabah. Oleh karena itu masyarakat cenderung memilih pembiayaan musyarakah. Dan terlihat juga bahwa pembiayaan mudharabah mengalami fluktuasi. Di tahun dimana pembiayaan musyarakah meningkat, belum tentu juga pembiayaan mudharabah ikut meningkat dari tahun sebelumnya.

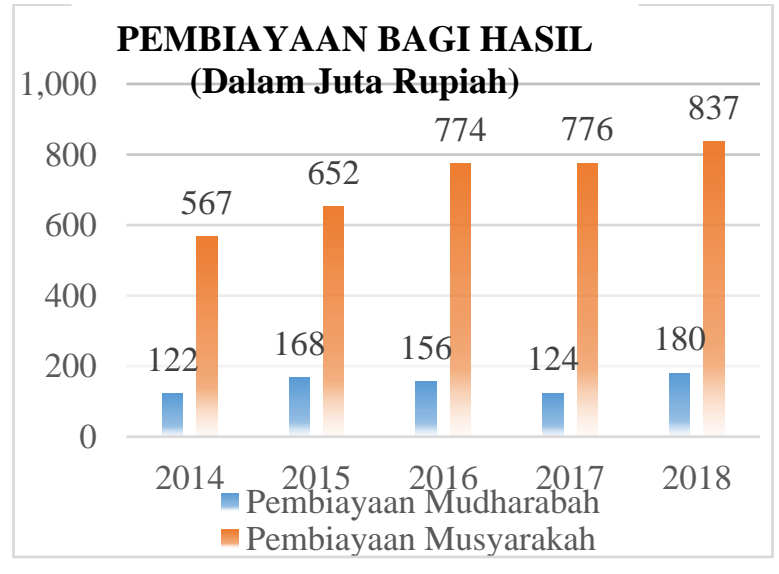

Sumber: OJK (diolah), 2019

Gambar 1 : Grafik Perkembangan

Pembiayaan Bagi Hasil Perbankan Syariah di Indonesia

Dalam gambar 2 dapat dilihat pembiayaan bermasalah mengalami fluktuasi. Pada tahun 2016 NPF menurun sebesar 1,02\% dari tahun sebelumnya dan meningkat lagi sebesar $0,4 \%$. Perbankan syariah di Indonesia terlihat terus berusaha untuk menjaga rasio 
pembiayaan bermasalah tetap rendah dari batas yang di tetapkan Bank Indonesia yaitu sebesar $<5 \%$.

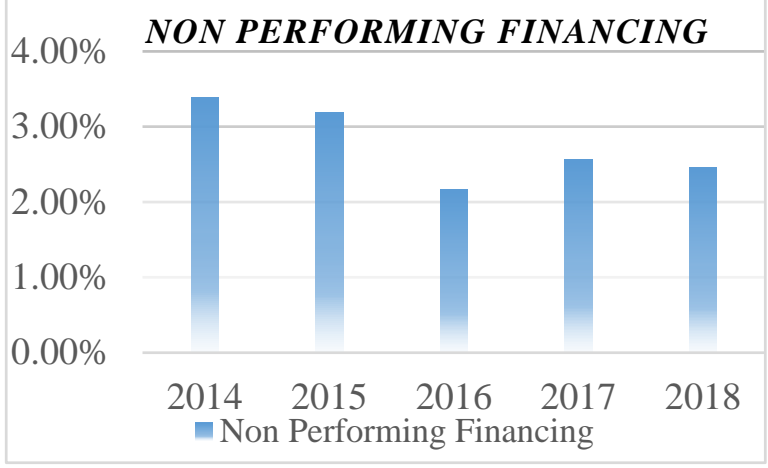

Sumber: OJK (diolah), 2019

Gambar 2: Grafik Perkembangan Non

Performing Financing Perbankan Syariah di Indonesia

Terlihat (gambar 3) bahwa perkembangan Capital Adequacy Ratio perbankan syariah di Indonesia mengalami perkembangan dari tahun 2016 - 2018 setelah mengalami sedikit penurunan di tahun 2015 . Ham tersebut dapat diartikan bahwa perbankan syariah di Indonesia selalu berusaha untuk meningkatkan kemampuan permodalan bank untuk mampu menyerap risiko kegagalan kredit yang mungkin terjadi

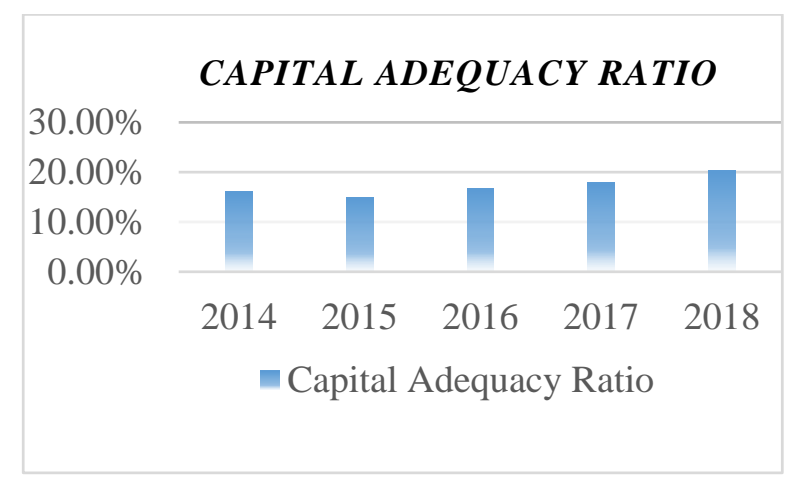

Sumber: OJK (diolah), 2019

Gambar 3: Grafik Perkembangan Capital Adequacy Ratio Perbankan Syariah di Indonesia
Return On Asset di Indonesia mengalami fluktuasi dari tahun ketahun (lihat gambar 4). Di tahun 2015 ROA mengalami penurunan dari tahun sebelumnya hampir 50\% dan pada tahun 2018 ROA mengalami peningkatan yang cukup signifikan dari tahun sebelunya yaitu lebih dari 50\%. Yang berarti di tahun tersebut perbankan syariah terus berusaha meningkatkan keuntung laba perusahaan.

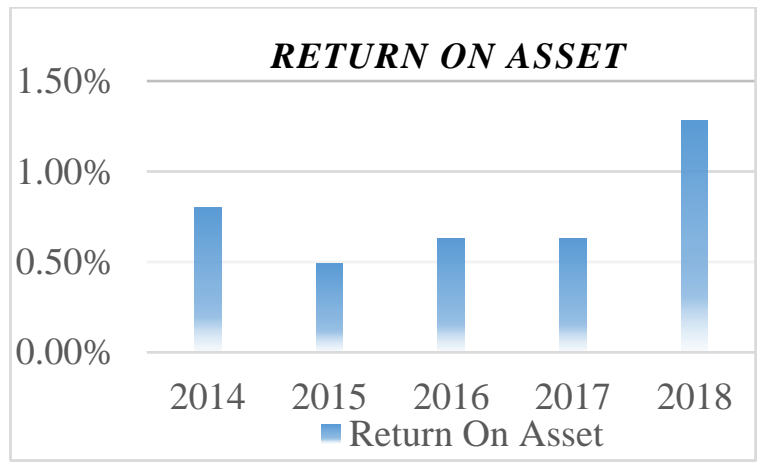

Sumber: OJK (diolah), 2019 Gambar 4: Grafik Perkembangan Return On Asset Perbankan Syariah di Indonesia

Penelitian Parasthiwi dan Budiasih (2019) menemukan bahwa Rasio Kecukupan Modal (CAR) tidak berpengaruh terhadap kinerja keuangan (ROA). Dan risiko kredit (NPF) belum mampu memoderasi pengaruh kecukupan modal (CAR) terhadap profitabilitas (ROA). Namun hasil penelitaian tersebut berbeda dengan yang dilakukan oleh Bernardin (2016) yang penelitiannya memiliki hasil bahwa Rasio Kecukupan Modal (CAR) berpengaruh terhadap ROA. 


\section{KAJIAN LITERATUR}

\section{Signaling Theory}

Signaling Theory menggambarkan perilaku ketika dua pihak (individu atau organisasi) memiliki akses ke informasi yang berbeda. Biasanya, satu pihak, pengirim, harus memilih apakah dan bagaimana berkomunikasi (atau memberi sinyal) informasi itu, dan pihak lain, penerima, harus memilih cara menginterpretasikan sinyal (Connelly, Certo, Ireland, \& Reutzel, 2011)

\section{Commercial Loan Theory}

Penelitian ini juga menggunakan Commercial Loan Theory dimana menekankan bahwa likuiditas bank akan terjamin apabila aset produktif disusun dari kredit jangka pendek yang mudah dicairkan selama bisnis dalam kondisi normal. Secara lebih spesifik, teori ini menyatakan bahwa bank-bank hanya akan memberikan kredit jangka pendek yang sangat mudah dicairkan/likuid ("Short Term, Self Liquiditing”) melalui pembayaran kembali/angsuran atas kredit tersebut sebagai sumber likuiditas (Tamunosiki, Baribefe, \& Blessing, 2017)

\section{Pembiayaan Bagi Hasil}

Definisi bagi hasil secara terminologi asing (Inggris) dikenal dengan profit sharing . Profit sharing dalam kamus ekonomi dapat diartikan sebagai pemberian laba. Sementara menurut Suwiknyo (2009) bila diartikan secara istilah profit sharing adalah distribusi beberapa bagian laba pada para pegawai dari suatu perusahaan. Bentuk-bentuk distribusi ini dapat berupa pembagian laba akhir, bonus prestasi, dan lain-lain. Dari beberapa penjelsana mengenai bagi hasil dapat diartikan bahwa bagi hasil merupakan sistem yang meliputi tata cara pembagian hasil usaha antara pemilik dana dan pengelola dana. Pembagian usaha. Perjanjian dapat dilakukan antara bank yang melakuakn fungsinya sebagai penyimpan dana, maupun antara bank dengan nasabah penerima dana. Produk simpanan tersebut yang menggunakan akad dengan prinsip kerjsama yang umum dikenal dengan akad mudharabah dan musyarakah. Lebih jauh prinsip mudharabah dapat dipergunakan sebagai dasar baik untuk produk pendanaan (tabungan dan deposito) maupun pembiayaan, sedangkan musyarakah lebih banyak untuk pembiayaan (Muhtarom, 2017).

\section{Pembiayaan Bermasalah / Non}

\section{Performing Financing (NPF)}

Non Performing Loan (NPL) atau Non Performing Financing (NPF) adalah suatu gambaran situasi, dimana persetujuan pengembalian pinjaman mengalami risiko kegagalan, bahkan cenderung menuju/mengalami rugi yang potensial (potential loss). Keberadaan pembiayaan bermasalah dalam jumlah yang tinggi akan menimbulkan kesulitan sekaligus akan 
menurunkan tingkat kesehatan bank yang bersangkutan (Riadi, 2014).

\section{Rasio Tingkat Kesehatan Bank}

Tingkat kesehatan bank merupakan penilaian atas laporan keuangan suatu bank pada saat tertentu sesuai dengan standar Bank Indonesia. Untuk menilai suatu kesehatan bank dapat dilihat dari beberapa segi. Penilaian ini bertujuan untuk menentukan apakah bank tersebut dalam kondisi yang sehat, cukup sehat, kurang sehat dan tidak sehat, sehingga Bank Indonesia sebagai pengawas dan pembina bank-bank dapat memberikan arahan atau bahkan dihentikan kegiatan operasinya (Kasmir, 2003). Kesehatan bank dijadikan tolak ukur bagi manajemen untuk menilai apakah pengelolaan bank dilakukan sesuai atau sejalan dengan asas - asas perbankan yang sehat dan sesuai dengan ketentuan yang berlaku.

\section{Kinerja Keuangan}

Kinerja keuangan adalah suatu analais yang dilakukan untuk melihat sejauh mana suatu perusahaan telah mengikuti aturanaturan pelaksanaan keuangan secara baik dan benar. Dari kinerja perusahaan maka dapat diketahui gambaran mengenai kondisi keuangan suatu perusahaan yang dapat dianalisis dengan menggunakan alat-alat analisis keuangan, sehingga dapat diketahui mengenai baik buruknya keadaan keuangan suatu perusahaan yang mencerminkan prestasi kerja dalam periode tertentu. Hal ini menjadi sangat penting agar sumber daya digunakan secara optimal dalam menghadapi perubahan lingkungan (Fahmi, 2011).

\section{Pengaruh Pembiayaan Bagi Hasil dan} Tingkat Kesehatan Bank terhadap Kinerja Keuangan dengan Pembiayaan

\section{Bermasalah sebagai Variable Pemoderasi}

Pembiayaan bagi hasil berpengaruh positif terhadap profitabilitas yang dihitung dengan Return On Asset (ROA). Semakin tinggi pembiayaan bagi hasil akan meningkatkan nisbah bagi hasil yang kemudian akan mempengaruhi tingginya Return On Asset (ROA). Sehingga, dapat disimpulkan bahwa semakin tinggi pembiayaan bagi hasil maka akan semakin tinggi pula profitabilitas bank umum Syariah yang dihitung dengan Return On Asset (ROA) (Rahayu, 2016).

\section{Pengaruh Pembiayaan Bagi Hasil}

\section{Terhadap Kinerja Keuangan}

Bagi Hasil adalah bentuk return (perolehan kembaliannya) dari kontrak investasi, dari waktu ke waktu, tidak pasti dan tidak tetap. Besar-kecilnya perolehan kembali itu bergantung pada hasil usaha yang benarbenar terjadi. Dengan demikian, dapat dikatakan bahwa sistem bagi hasil merupakan salah satu praktik perbankan syariah (Karim, 2004).

\section{Pengaruh Tingkat Kesehatan Bank} Terhadap Kinerja Keuangan 
Menurut Haryanti (2018), Capital Adequacy Ratio merupakan rasio kecukupan modal yang menunjukkan kemampuan perbankan dalam menyediakan dana yang digunakan untuk mengatasi kemungkinan risiko kerugian. Pengaruh CAR terhadap ROA menunjukkan bahwa secara parsial variabel CAR berpengaruh positif tetapi tidak signifikan terhadap variabel ROA.

Pengaruh Pembiayaan Bagi Hasil terhadap Kinerja Keuangan dengan Pembiayaan Bermasalah sebagai Variable Pemoderasi

Pembiayaan bagi hasil yang merupakan salah satu produk penyaluran dana pada bank syariah harus memperhatikan pengendalian dan pengawasan dalam produk bagi hasil ini, karena apabila kurangnya pengendalian dan pengawasan maka resiko terjadinya pembiayaan bermasalah akan semakin bertambah sehingga akan mempengaruhi kinerja keuangan bank syariah (Perdanasari, 2017).

\section{Pengaruh Tingkat Kesehatan Bank terhadap Kinerja Keuangan dengan} Pembiayaan Bermasalah sebagai Variable

\section{Pemoderasi}

Menurut Iman (2017) Non performing financing memoderasi antar capital adequacy ratio dan return on asset. Hal ini berarti bahwa non performing financing merupakan variabel moderating yang memperlemah hubungan antara capital adequacy ratio dengan return on asset. Semakin kecil non performing financing yang dimiliki perusahaan maka perusahaan memiliki potensi return on asset yang tinggi pada tahun berikutnya apabila perusahaan juga memiliki capital adequacy ratio yang tinggi.

\section{Kerangka Pemikiran}

Menurut Umar (2008) dalam bukunya dijelaskan seluruh kegiatan penelitian, mulai dari tahap awal sampai tahap akhir harus merupakan suatu kesatuan kerangka pemikiran yang utuh dalam rangka mencari jawaban-jawaban ilmiah terhadap masalahmasalah yang di teliti. Kerangka Pemikiran dibuat dalam suatu skema, sehingga isi penelitian secara keseluruhan diketahui dengan jelas, mulai dari mekasnisme ketersediaan data, pengolahan dan penyajiannya.

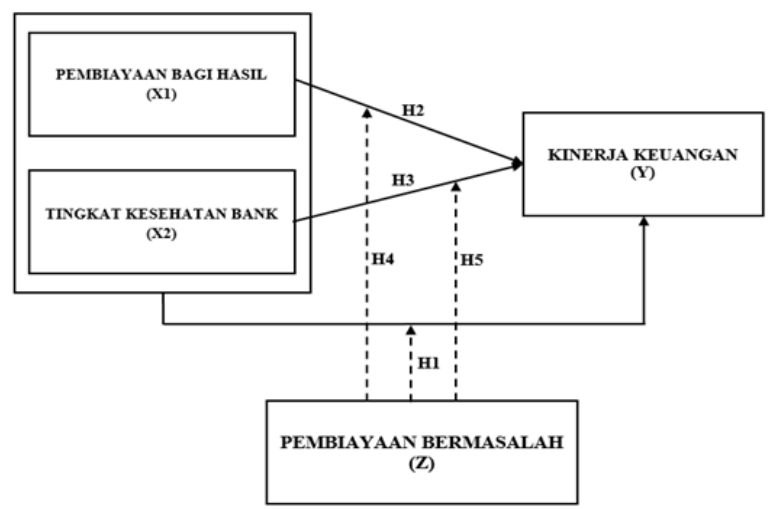

Gambar 5: Kerangka Pemikiran

\section{Hipotesis}

1. $\mathrm{H}_{1}$ : Diduga pembiayaan Bagi Hasil dan Tingkat Kesehatan Bank memiliki pengaruh terhadap Kinerja Keuangan dengan pembiayaan Bermasalah sebagai Variabel Pemoderasi. 
2. $\mathrm{H}_{2}$ : Diduga Pembiayaan Bagi Hasil memiliki pengaruh terhadap Kinerja Keuangan.

3. $\mathrm{H}_{3}$ : Diduga Tingkat Kesehatan bank memiliki pengaruh terhadap Kinerja Keuangan.

4. $\mathrm{H}_{4}$ : Diduga Pembiayaan Bagi Hasil memiliki pengaruh terhadap Kinerja Keuangan dengan Pembiayaan Bermasalah sebagai Variabel Pemoderasi.

5. $\mathrm{H}_{5}$ : Diduga Pembiayaan Tingkat Kesehatan Bank memiliki pengaruh terhadap Kinerja Keuangan dengan Pembiayaan Bermasalah sebagai Variabel Pemoderasi

\section{METODOLOGI PENELITIAN}

\section{Jenis Penelitian}

Jenis penelitian dalam penulisan kali ini menggunakan metode analisis kuantitatif asosiatif, yaitu tipe penelitian untuk menganalisis pengaruh beberapa variabel terhadap variabel lainnya yang dilakukan melalui pemecahan masalah yang digambarkan dari objek penelitian untuk mengetahui hubungan yang signifikan antara variabel yang diteliti sehingga mengasilkan kesimpulan berupa angka-angka yang nantinya akan dijadikan sebagai dasar pengambilan keputusan (Sugiyono, 2017).

\section{Waktu dan Tempat Penelitian}

Penelitian ini mengambil data sekunder yang diperoleh dari website perusahaan yang diteliti, dalam hal ini yaitu perusahaan perbankan syariah yang terdaftar di Bank Indonesia dengan periode penelitian 5 tahun terhitung dari tahun 2014-2018. Data tersebut digunakan bagi peneliti untuk mendapatkan informasi agar dapat di lakukan penelitian lebih lanjut. Penelitian dilakukan pada Juli September 2019.

\section{Subjek Penelitian}

Menurut Sugiyono (2017) populasi adalah wilayah generalisasi yang terdiri atas obyek/subyek yang mempunyai kualitas dan karakteristik tertentu yang ditetapkan oleh peneliti untuk dipelajari dan kemudian ditarik kesimpulannya dan sampel adalah bagian dari jumlah dan karakteristik yang dimiliki oleh populasi tersebut. Untuk pengambilan sample penelitian digunakan teknik purposive sampling yang dimana adalah teknik penentuan sample dengan pertimbangan tertentu.

Adapun kriteria yang menjadi pertimbangan penelitian dalam pengambilan sampel yaitu:

1) Bank Umum Syariah di Indonesia yang terdaftar di BI

2) Bank yang menerbitkan laporan keuangan secara terus menerus selama periode penelitian (Tahun 2014-2018), dan 
3) Bank Umum Syariah yang memiliki kelengkapan data berdasarkan variabel penelitian terkait pada laporan keuangan tahunan periode 2014-2018 yang telah dipublikasikan.

Dari beberapa kriteria tersebut, setelah dilakukan pengolahan sampel maka didapat beberapa objek penelitian yang tidak sesuai dengan kriteria yang disebutkan.

\section{Instrumen Penelitian}

Instrumen penelitian adalah suatu alat yang digunakan untuk mengukur fenomena alam maupun social yang diamati, secara spesifik semua fenomena ini disebut variabel penelitian (Sugiyono, 2017). Instrumen peneltianyang digunakan adalah data yang diambil dari laporan keuangan perusahaan yang terdiri dari pembiayaan bagi hasil, rasio CAR, rasio ROA dan rasio NPF.

\section{Data dan Teknik Pengumpulan}

Data yang digunakan dalam penelitian ini adalah berupa data sekunder yaitu berupa Laporan Keuangan dari 11 bank yaitu PT. Bank BCA Syariah, PT. Bank BNI Syariah, PT. Bank BRI Syariah, PT. Bank Bukopin Syariah, PT. Bank Jabar Banten Syariah, PT. Bank Mandiri Syariah, PT. Bank Maybank Syariah Indonesia, PT. Bank Mega Syariah Indonesia, PT. Bank Muamalat Indonesia, PT. Bank Panin Syariah, PT. Bank Victoria Syariah.

\section{Tekhik Analisis Data}

Teknik analisis yang digunakan adalah dengan menggunakan uji model regrasi data panel, uji asumsi klasik, regresi linear berganda, koefisien kolerasi determinasi berganda, uji t, uji F dan uji Moderate Regression Analysis

\section{HASIL PENELITIAN DAN \\ PEMBAHASAN}

\section{Uji Simultan (Uji F)}

Uji statistik f pada dasarnya menunjukan apakah semua variabel independen yang dimasukan dalam model mempunyai pengaruh secara bersama-sama terhadap variabel dependen (Priyatno, 2012).

Dalam tabel 1 diperoleh nilai F-Statistics sebesar 5.159852 dengan $p$ value sebesar 0.000701 dimana $<0,05$ atau batas kritis penelitian dengan hasil $\mathrm{f}$ tabel yang lebih besar sebesar 2,79 atau $\mathrm{F}$ hitung $\leq \mathrm{F}$ tabel, sehingga dapat disimpulkan menerima $\mathrm{H}_{1}$. Menerima $\mathrm{H}_{1}$ dalam uji simultan berarti bahwa variabel independent secara serentak mempengaruhi secara signifikan variabel dependent.

\section{Uji Parsial (Uji t)}

Uji statistik $t$ pada dasarnya menunjukkan seberapa jauh satu variabel independen secara individual dalam menerangkan variabel dependen. Uji $\mathrm{t}$ ini dilakukan dengan membandingkan nilai $\mathrm{t}$ hitung dan t tabel. Level of Significance yang 
digunakan adalah 5\% dan dasar pengambilan keputusan apakah Ha diterima atau ditolak.

Tabel 1. Hasil Uji F

\begin{tabular}{|c|c|c|}
\hline \multirow[t]{2}{*}{ Variable } & \multicolumn{2}{|c|}{ 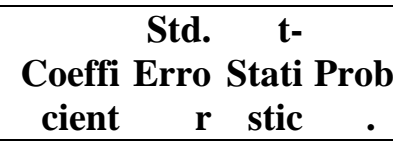 } \\
\hline & \multicolumn{2}{|c|}{ 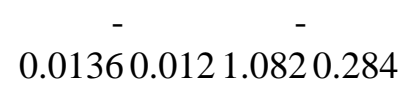 } \\
\hline $\mathrm{C}$ & $\begin{array}{lll}54 & 615 & 392\end{array}$ & \\
\hline \multicolumn{3}{|c|}{ PEMBIAYAAN_BAGI 5.53E- 3.471 .5950 .117} \\
\hline _HASIL & \multicolumn{2}{|c|}{0.05510 .0212 .6240 .011} \\
\hline CAR & \multicolumn{2}{|c|}{$\begin{array}{cccc}11 & 002 & 084 & 6 \\
0.2664 & 0.481 & 0.552 & 0.582\end{array}$} \\
\hline NPF & \multicolumn{2}{|l|}{$\begin{array}{rrr}54 & 878 & 948 \\
- & & -\end{array}$} \\
\hline \multicolumn{3}{|c|}{ PEMBIAYAAN_BAGI 3.51E- 1.921 .8320 .072} \\
\hline _HASIL*NPF & \multicolumn{2}{|c|}{2.56571 .2991 .9730 .054} \\
\hline \multirow[t]{2}{*}{$\mathrm{CAR} * \mathrm{NPF}$} & $92 \quad 959 \quad 746$ & \\
\hline & \\
\hline R-squared & $\begin{array}{l}13 \mathrm{var} \\
\text { S.D. }\end{array}$ & 802 \\
\hline Adjusted R-squared & $\begin{array}{c}\text { 0.2780dependent } \\
\text { 68var } \\
\text { Akaike }\end{array}$ & $\begin{array}{r}0.034 \\
318\end{array}$ \\
\hline S.E. of regression & $\begin{array}{l}0.0291 \text { info } \\
59 \text { criterion }\end{array}$ & $\begin{array}{r}4.129 \\
451\end{array}$ \\
\hline
\end{tabular}

\subsection{Uji t Pembiayaan Bagi Hasil}

Uji hipotesis (Uji t) digunakan untuk menguji signifikansi variabel secara parsial. Hasil dari uji hipotesis menunjukkan nilai signifikansi pembiayaan bagi hasil sebesar 0,4412, lebih besar dari taraf signifikansi $\alpha=0,05$, sehingga $\mathrm{H}_{2}$ ditolak. Hal ini berarti pembiayaan bagi hasil memiliki pengaruh negatif ditunjukan dengan Coefficient yang bernilai negatif yaitu -1.12E-12 dan tidak signifikan atau tidak berpengaruh yang ditunjukan oleh nilai Prob. yang lebih besar dari 0,05 pada kinerja keuangan.
Tabel 2: Hasil Uji t Pembiayaan Bagi Hasil

Coeffic Std. Statis

Variable ient Error tic Prob.

$\begin{array}{lllll}\mathrm{C} & 42 & 872 & 898 & 1\end{array}$

\begin{tabular}{|c|c|c|c|}
\hline PEMBIAYAAN_B & $-1.12 \mathrm{E}-$ & 1.44E 0.77 & 0.441 \\
\hline GI_HASIL & 12 & -12971 & 2 \\
\hline & 0.0112 & $\begin{array}{c}\text { Mean } \\
\text { dependent }\end{array}$ & $\begin{array}{c}0.019 \\
802\end{array}$ \\
\hline R-squared & 53 & $\begin{array}{l}\text { var } \\
\text { S.D }\end{array}$ & \\
\hline & 0.0074 & dependent & 0.034 \\
\hline Adjusted R-squared & 23 & var & 318 \\
\hline & 0.4412 & & \\
\hline Prob(F-statistic) & 15 & & \\
\hline
\end{tabular}

\subsection{Uji t Capital Adequacy Ratio (CAR)}

Variabel CAR memiliki taraf signifikansi sebesar 0,0056 yang berarti lebih kecil dari taraf signifikansi $\alpha=0,05$ sehingga $\mathrm{H}_{3}$ diterima. Hal ini menunjukkan bahwa struktur modal berpengaruh positif signifikan pada profitabilitas kinerja perusahaan. Hal ini ditunjukan dengan Coefficient yang bernilai positif yaitu 0.056699 dan signifikan yang ditunjukan oleh nilai Prob. yang lebih kecil dari 0,05 pada kinerja keuangan.

Atau dapat dilihat dari Nilai thitung CAR sebesar 2.887159 dengan nilai signifikansi 0,0056 dan nilai t tabel 2,00758. Karena nilai t hitung > nilai t tabel dan nilai signifikansi lebih kecil dari 0,05 maka model regresi dapat digunakan untuk memprediksi

kinerja keuangan (ROA) atau dapat disimpulkan bahwa CAR berpengaruh positif dan signifikan tehadap kinerja keuangan (ROA). 
Tabel 3: Hasil Uji t CAR

\begin{tabular}{|c|c|c|c|}
\hline Variable & Coefficien & $\begin{array}{cc}\text { Std. } & \text { t- } \\
\text { Error } & \text { Statistic }\end{array}$ & Drob \\
\hline \multirow[b]{2}{*}{$\mathrm{C}$} & & $0.00642 \quad 0.95207$ & \\
\hline & 0.006119 & 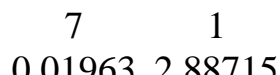 & 0.3454 \\
\hline CAR & 0.056699 & 8.09 & 0.0056 \\
\hline R- & & \multirow{2}{*}{$\begin{array}{l}\text { Mean dependent } \\
\text { var }\end{array}$} & 0.01980 \\
\hline squared & 0.135903 & & 2 \\
\hline \multicolumn{4}{|l|}{ Adjusted } \\
\hline $\mathrm{R}-$ & & \multirow{3}{*}{$\begin{array}{l}\text { S.D. dependent } \\
\text { var }\end{array}$} & 0.03431 \\
\hline squared & 0.119599 & & 8 \\
\hline S.E. of & & & - \\
\hline regressio & & \multirow{2}{*}{$\begin{array}{l}\text { Akaike info } \\
\text { criterion }\end{array}$} & 3.99798 \\
\hline n & 0.032200 & & 8 \\
\hline \multicolumn{3}{|l|}{$\begin{array}{l}\text { Sum } \\
\text { squared }\end{array}$} & $\begin{array}{c}- \\
3.92499\end{array}$ \\
\hline $\begin{array}{l}\text { resid } \\
\text { Log }\end{array}$ & 0.054954 & Schwarz criterion & $\begin{array}{l}4 \\
-\end{array}$ \\
\hline likelihoo & & \multirow{4}{*}{$\begin{array}{l}\text { Hannan-Quinn } \\
\text { criter. } \\
\text { Durbin-Watson } \\
\text { stat }\end{array}$} & 3.96976 \\
\hline d & 111.9447 & & 0 \\
\hline & & & 1.52464 \\
\hline $\begin{array}{l}\text { F-statistic } \\
\text { Prob(F- } \\
\text { statistic) }\end{array}$ & 0.005615 & & \\
\hline
\end{tabular}

\section{Uji Analisis MRA (Moderated}

\section{Regession Analisys)}

Pengujian hipotesis dalam penelitian ini dilakukan menggunakan Moderated Regression Analysis (MRA). MRA adalah salah satu alat khusus dalam pengujian regresi linear berganda, yang dalam persamaan regresinya terkandung unsur interaksi (Ghozali, 2012). Persamaan regresi untuk penelitian ini adalah sebagai berikut:

$\mathrm{Y}=\alpha+\beta 1 \mathrm{X} 1+\beta 2 \mathrm{X} 2+\beta 3 \mathrm{Z}+\beta 4 \mathrm{X} 1 * \mathrm{Z}+\beta 5 \mathrm{X} 2 *$ $\mathrm{Z}+\mathrm{e}$

Hasil dari Uji MRA berganda menurut tabel 4 diketahui bahwa pembiayan bermasalah (NPF) tidak dapat memoderasi pembiayaan bagi hasil terhadap kinerja keuangan (ROA) yang di tunjukan dengan nilai $p$ value atau Prob. sebesar 0.0729 dimana $>0,05$ atau batas kritis penelitian dengan $\mathrm{t}$ tabel lebih besar yaitu 2,00758 yang berarti tidak ada pengaruh. Untuk variabel tingkat kesehatan bank (CAR), pembiayan bermasalah (NPF) juga tidak dapat memoderasi CAR terhadap ROA yang ditunjukan dengan nilai $p$ value sebesar 0.0541 dimana $>0,05$ atau batas kritis penelitian dengan $\mathrm{t}$ tabel lebih besar yaitu 2,00758 yang berarti tidak ada pengaruh.

Tabel 4: Hasil Uji MRA

\begin{tabular}{ccccc}
\hline & \multicolumn{4}{c}{$\mathrm{t}-$} \\
Variable & $\begin{array}{c}\text { Coeffi } \\
\text { cient }\end{array}$ & Std. & Statis \\
& - & tic & Prob. \\
C & 0.0136 & 0.012 & 1.082 & 0.284 \\
PEMBIAYAAN_BAGI & 54 & 615 & 392 & 4 \\
_HASIL & 12 & -12 & 294 & 1 \\
& 0.0551 & 0.021 & 2.624 & 0.011 \\
CAR & 11 & 002 & 084 & 6 \\
& 0.2664 & 0.481 & 0.552 & 0.582 \\
NPF & 54 & 878 & 948 & 8
\end{tabular}

PEMBIAYAAN_BAGI 3.51E-1.92E 1.8320 .072 $\begin{array}{lllll}\text { HHASIL*NPF } & 10 & -10 & 887 & 9\end{array}$

2.56571 .2991 .9730 .054 $\begin{array}{lllll}\text { CAR*NPF } & 92 & 959 & 749 & 1\end{array}$

0.3449 dependent 0.019 R-squared $\quad 13 \quad$ var 802

0.2780 dependent 0.034 Adjusted R-squared $\quad 68 \quad$ var $\quad 318$

S.E. of regression

0.0291 Akaike info 4.129
59 criterion 451

0.0416 Schwarz 3.910

62 criterion 469 Hannan- -

119.55 Quinn 4.044

Log likelihood $\quad 99$ criter. 769

5.1598 Durbin- 2.244

F-statistic $\quad 52$ Watson stat 261

0.0007

Prob(F-statistic) $\quad 01$ 


\section{Uji Koefisien Determinasi (Adjust $\mathbf{R}_{\mathbf{2}}$ )}

Nilai adjusted $R$ Square artinya nilai $R$ Square yang telah terkoreksi oleh nilai standar error. Jika nilai standar error lebih kecil dari pada nilai standar deviasi variabel response yangditunjukan oleh label "S.D. dependent var" maka dapat diartikan bahwa model regresi valid sebagai model prediktor, dapat di simpulkan bahwa pembiayaan bagi hasil dan CAR hanya mempengaruhi sebesar $16,6 \%$ saja yang berarti $83,4 \%$ nya di pengaruhi oleh faktor lain.

\section{SIMPULAN DAN SARAN}

Berdasarkan pada data yang sudah dikumpulkan dan diolah serta diuji serta analisis yang telah dilakukan maka dapat ditarik kesempulan yaitu, Pembiayan bermasalah (NPF) tidak dapat memoderasi pembiayaan bagi hasil. Untuk variabel tingkat kesehatan bank (CAR), pembiayan bermasalah (NPF) juga tidak dapat memoderasi CAR terhadap ROA. Yang dapat disimpulkan bawa pembiayaan bermasalah belum mampu memoderasi kedua variabel tersebut terhadap kinerja keuangan. Terdapat pengaruh Pembiayaan bagi hasil terhadap kinerja keuangan $\mathrm{n}$ (ROA). Tingkat kesehatan bank berpengaruh positif signifikan pada profitabilitas kinerja perusahaan. Dan Interaksi Non Performing Financing (NPF), Capital Adequacy Ratio (CAR) terhadap Retun On Asset (ROA) dengan hasil tidak signifkan atau tidak berpengaruh. Nilai NPF yang masih berada dibawah batas maksimum tidak berdampak pada peningkatan atau penurunan kecukupan modal bank dan tidak berdampak pada profitabilitas bank.

\section{Saran}

Untuk mencapai tujuan meningkatkan laba/profitabilitas suatu perbankan diharapkan pihak manajemen perbankan dapat melakukan penanganan yang serius pada rasio keuangan, seperti menjaga nilai NPF supaya berada pada posisi aman, menjaga tingkat kecukupan modalnya, sehingga pada akhirnya dengan tercukupinya tingkat kecukupan modal, kinerja keuangan bank tersebut akan meningkat. Pihak bank hendaknya menjaga kualitas aktiva produktif, melakukan perencanaan, pengaturan pengevaluasian pemberian kredit dengan lebih cermat dan lebih selektif dengan menggunakan prinsip kehati-hatian.

Bagi pihak investor diharapkan memenuhi pengembalian dana pembiayaan bagi hasil dengan benar sesuai perjanjian agar tidak merugikan pihak bank juga perlu memperhatikan kecukupan modal yang dapat dijadikan oleh investor sebagai bahan pertimbangan untuk menentukan strategi investasinya. Karena semakin besar capital adequacy ratio suatu bank, diharapkan semakin tinggi juga return on asset yang akan diperoleh bank tersebut. Bagi Akademisi Penelitian ini dapat bermanfaat dijadikan 
bahan referensi dan dokumentasi bagi pihak universitas sebagai bahan acuan penelitian yang akan datang. Selain itu diharapkan agar pihak universitas untuk lebih menambah lagi referensi baik yang berupa jurnal atau bukubuku yang terkait keuangan dan penelitian terkait. Penelitian yang akan datang disarankan untuk menambah variabel seperti Dana Pihak Ketiga, Pembiayaan Jual Beli, Pembiayaan Sewa, BOPO, FDR dan sebagainya yang mungkin dapat mempengarhui ROA atau menambah alat ukur agar hasil penelitian lebih spesifik dan selalu memperbarui bahan penelitian agar penelitian selalu terupdate.

\section{DAFTAR PUSTAKA}

Bernardin, D. E. Y. (2016). Pengaruh CAR dan LDR Terhadap Return On Asstes. Jurnal Ecodemica: Jurnal Ekonomi, Manajemen, Dan Bisnis. https://doi.org/10.31311/JECO.V4I2.33 4

Connelly, B. L., Certo, S. T., Ireland, R. D., \& Reutzel, C. R. (2011). Signaling theory: A review and assessment. Journal of Management. https://doi.org/10.1177/0149206310388 419

Fahmi, I. (2011). Analisis Laporan Keuangan. Lampulo: Alfabeta.

Haryanti, Y. (2018). Pengaruh Rasio Kesehatan Bank terhadap Kinerja Keuangan Bank Umum Syariah di Indonesia Periode 2012-2016. UIN Raden Intan Lampung.

Iman, F. (2017). Pengaruh Capital Adequacy
Ratio, Financing Deposit Ratio Dan Operational Efficiency Ratio Terhadap Return on Assets Dengan Non Performing Financing Sebagai Variabel Moderating pada Bank Umum Syariah di Indonesia. UIN Alauddin Makassar.

Karim, A. (2004). Bank Islam Analisis Fiqh \& Keuangan. Jakarta: PT. Raja Grafindo Persada.

Kasmir, S. M. (2003). Bank dan Lembaga Keuangan Lainnya. Jakarta: PT. Raja Grafindo Persada.

Muhtarom, I. H. (2017). Penetapan Bagi Hasil Pada Akad Mudharabah Dalam Kegiatan Pertanian di KSPPS Tamziz. Bina Utama Cabang Batur Banjarnegara. UIN Walisongo.

Nizar, A. S., \& Anwar, M. K. (2015). Pengaruh Pembiayaan Jual Beli, Pembiayaan Bagi Hasil Dan Intellectual Capital Terhadap Kinerja Keuangan Bank Syariah. AKRUAL: Jurnal Akuntansi.

https://doi.org/10.26740/jaj.v6n2.p130146

Parasthiwi, A. A. T. D., \& Budiasih, I. G. A. N. (2019). Pengaruh Kecukupan Modal, Penyaluran Kredit dan Ukuran Perusahaan Pada Profitabilitas Dengan Risiko Kredit Sebagai Pemoderasi. EJurnal Akuntansi. https://doi.org/10.24843/eja.2019.v26.i0 1.p29

Priyatno, D. (2012). Cara Kiat Belajar Analisis Data dengan SPSS 20 (1st ed.). Yogyakarta: Andi.

Rahayu, A. R. (2016). engaruh Debt Financing dan Equity Financing Terhadap Kenierja Keuangan Bank Syariah dengan Non Performing Financing Sebagai Variabel Moderasi (studi pada Bank Umum Syariah yang listing di BI). Universitas Islam Negeri 
Alauddin.

Riadi, M. (2014). Pembiayaan Bermasalah KajianPustaka.com. Retrieved February 26, 2014, from https://www.kajianpustaka.com/2014/0 2/pembiayaan-bermasalah.html

Rochmanika, R., \& Rahman, A. F. (2012). Pengaruh Pembiayaan Jual Beli, Pembiayaan Bagi Hasil, dan Rasio Non Performing Financing Terhadap Profitabilitas Bank Umum Syariah di Indonesia. IQTISHODUNA, 8(1). Retrieved from http://ejournal.uinmalang.ac.id/index.php/ekonomi/article/ view/1768

Sugiyono. (2017). Metode Penelitian Kuantitatif Kualitatif dan $R \& D$. Bandung: Alfabeta.

Suwiknyo, M. D. (2009). Akuntansi Perbankan Syariah. Yogyakarta: Trust Media.

Tamunosiki, K., Baribefe, I., \& Blessing, O. (2017). Liquidity and Performance of Nigerian Banks. Journal of Accounting and Financial Management ISSN.

Umar, H. (2008). Metode Penelitian untuk Skripsi dan Tesis Bisnis. Jakarta: PT. Raja Grafindo Persada.

Utami, N. F. (2014). Pengaruh Pembiayaan Jual Beli, Pembiayaan Bagi Hasil, Pembiayaan Sewa Terhadap Kinerja Keuangan (Studi Kasus pada Bank Syariah Mandiri). UIN Sunan Kali Jaga. 